Research Article

\title{
Investigating the Effects of Chopped Basalt Fiber on the Performance of Porous Asphalt Mixture
}

\author{
Sheng Wang ${ }^{D}$, Aihong Kang $(\mathbb{D}$, Peng Xiao, Bo Li, and Weili Fu \\ College of Civil Science and Engineering, Yangzhou University, Yangzhou, Jiangsu 225009, China \\ Correspondence should be addressed to Aihong Kang; kahyzu@163.com
}

Received 17 March 2019; Revised 21 May 2019; Accepted 18 June 2019; Published 2 July 2019

Guest Editor: Jose Norambuena-Contreras

Copyright (c) 2019 Sheng Wang et al. This is an open access article distributed under the Creative Commons Attribution License, which permits unrestricted use, distribution, and reproduction in any medium, provided the original work is properly cited.

\begin{abstract}
Porous asphalt mixture is a type of asphalt mixture with good drainage. However, it has poor tensile strength performance and durability. Chopped basalt fibers (CBF) have been proved to be an effective additive to improve the mechanical and fatigue performance of asphalt mixtures, but little attention has been paid on porous asphalt mixture. This paper examined the effect of chopped basalt fibers with different lengths (nonfiber, $3 \mathrm{~mm}, 6 \mathrm{~mm}, 9 \mathrm{~mm}$, and $12 \mathrm{~mm}$ ) and contents $(3 \%$ and $4 \%$ ) on the performance of the porous asphalt mixture. A series of tests were conducted to figure out the optimum fiber length and content, including draindown test, cantabro abrasion test, freeze-thaw split tensile test, wheel tracking test, low-temperature cracking resistance test, and four-point bending beam test. Thereafter, indirect tensile tests at different temperatures were conducted to investigate the tensile strength properties of porous asphalt mixtures with optimum fiber length and content. Besides, the macroscopic and microscopic morphology of fracture sections of the samples after indirect tensile tests were studied by using a single-lens reflex (SLR) camera and scanning electron microscopy (SEM) so as to further explore the reinforced mechanism of chopped basalt fibers. The results show that the addition of chopped basalt fibers can generally improve the performance of porous asphalt mixture since chopped basalt fibers form a three-dimensional network structure in the porous asphalt mixture.
\end{abstract}

\section{Introduction}

Porous asphalt mixture is widely used for its remarkable water permeability, good skid resistance performance, and the function of reducing the pavement temperature [1]. However, due to the stone skeleton structure and big air voids, the structural strength of the porous asphalt mixture mainly comes from the point-to-point intercontact of coarse aggregates $[2,3]$. Compared with the conventional dense-graded asphalt mixtures, the contact area between the aggregates decreased by about $25 \%$, resulting in stress concentration at the contact points. Therefore, the tensile strength of the porous asphalt mixture is greater than that of the conventional asphalt mixture, which will make the porous asphalt mixture suffer more thermal cracking or low-temperature cracking and prone to be loose or raveling [4-6]. Besides the limitations of porous asphalt mixtures, the increasing traffic volume is another challenging for the use of porous asphalt mixtures. Thus, it is necessary to comprehensively improve the performance of porous drainage pavement.
Adding additives to the asphalt or asphalt mixture has become one of the technical means to solve this problem [7]. In recent years, fibers have widely been used as an additive in asphalt mixtures. The outstanding characteristics of fiber asphalt mixture can prevent the expansion of asphalt pavement cracks, reduce the occurrence of high-temperature rutting, make up for the shortcomings of low-temperature brittleness, and relieve water damage on the pavements so as to significantly extend the service life of asphalt pavements.

At present, most of the fibers used in asphalt mixtures include organic fibers (lignin fibers, polymer fibers, and polyester fibers) and inorganic fiber (chopped basalt fibers, etc.) [8-10]. Previous studies have shown that organic fibers have some disadvantages such as low strength and modulus, poor resistance to high and low temperatures, and high water absorption. Besides, they also present degradation, oxidation reaction, and curling problems during mixing and paving process $[7,11,12]$. The chopped basalt fiber is made of natural basalt rocks, which are broken and thrown into a 
melting furnace. After being melted at $1450^{\circ} \mathrm{C}$ to $1500^{\circ} \mathrm{C}$, the continuous fibers were formed by drawing from the platinum-rhodium alloy wire drawing plate [13-15]. As a new type of mineral fiber, chopped basalt fiber has the advantages of high strength, good acid and alkali resistance, high- and low-temperature resistance, good dispersibility, and environment friendly [16-18]. A large number of previous studies have focused on the effects of chopped basalt fiber on the performance of conventional asphalt mixture and proved the positive effects. However, little attention has been paid on porous asphalt mixture [19-22]. Therefore, the effect of chopped basalt fiber on the performance of porous asphalt mixture needs to be comprehensively studied [23, 24].

Therefore, this paper examined the effect of chopped basalt fibers with varied lengths (nonfiber, $3 \mathrm{~mm}, 6 \mathrm{~mm}$, $9 \mathrm{~mm}$, and $12 \mathrm{~mm}$ ) and contents (3\% and $4 \%$ ) on the performance of the porous asphalt mixture. And draindown test, cantabro abrasion test, freeze-thaw split test, wheel tracking test, low-temperature bending test, and four-point bending test were conducted, respectively. The tensile properties of porous asphalt mixture with chopped basalt fiber at different temperatures $\left(-25^{\circ} \mathrm{C},-15^{\circ} \mathrm{C},-5^{\circ} \mathrm{C}, 5^{\circ} \mathrm{C}\right.$, $15^{\circ} \mathrm{C}$, and $25^{\circ} \mathrm{C}$ ) were explored by the indirect tensile test. Morphology analysis of fracture sections was also studied to further understand the reinforced mechanism of CBF by SEM.

\section{Materials and Methods}

\subsection{Materials}

2.1.1. Asphalt. A type of radial styrene-butadiene-styrene(SBS-) modified asphalt was used in the research. The properties of asphalt are shown in Table 1.

2.1.2. Aggregates. Basalt coarse aggregates (minimum size of aggregate $\geq 4.75 \mathrm{~mm}$ ) and limestone fine aggregates (maximum size of aggregate $<4.75 \mathrm{~mm}$ ) were used, respectively. The properties of the aggregates are listed in Tables 2 and 3, respectively.

2.1.3. Mineral Filler. The mineral filler was produced by limestone. Some properties are shown in Table 4.

2.1.4. Additives. High-viscosity agent (HVA) and chopped basalt fiber were used as additives in this study. HVA is a commonly used additive for porous asphalt mixture to enhance the viscosity of asphalt and improve the bonding between asphalt and aggregates, as shown in Figure 1. HVA is added with the aggregates and blended during the mixing process, which is called "dry process." The dose of HVA was $0.3 \%$ by weight of the asphalt. Some properties are shown in Table 5.

Chopped basalt fiber was obtained from Jiangsu Province (Figure 2). Chopped basalt fiber was added by weight of the total aggregates. Properties of CBF are shown in Table 6.

Figure 3 shows the scanning electron microscope (SEM) micrographs of chopped basalt fibers with the magnification
TABle 1: Properties of the asphalt.

\begin{tabular}{lcc}
\hline Properties & Results & Specification requirements \\
\hline Penetration $\left(25^{\circ} \mathrm{C}, 0.1 \mathrm{~mm}\right)$ & 66.0 & $\geq 50$ \\
Softening point $\left({ }^{\circ} \mathrm{C}\right)$ & 80 & $\geq 75$ \\
Ductility $(\mathrm{cm})$ & 29 & $\geq 20$ \\
Viscosity $(\mathrm{Pa} \cdot \mathrm{s})$ & 2.302 & $2.2 \sim 3.0$ \\
Elastic recovery $\left(25^{\circ} \mathrm{C}, \%\right)$ & 98.7 & $\geq 90$ \\
Density $\left(\mathrm{g} \cdot \mathrm{cm}^{-3}\right)$ & 1.023 & Measured \\
Penetration ratio $\left(25^{\circ} \mathrm{C}, \%\right)$ & 85.7 & $\geq 65$ \\
\hline
\end{tabular}

TABle 2: Properties of the coarse aggregates.

\begin{tabular}{lccc}
\hline \multirow{2}{*}{ Properties } & \multicolumn{2}{c}{ Results } & Specification \\
& $5 \sim 10 \mathrm{~mm}$ & $10 \sim 15 \mathrm{~mm}$ & requirements \\
\hline Apparent density $\left(\mathrm{g} / \mathrm{cm}^{3}\right)$ & 3.002 & 2.955 & $\geq 2.70$ \\
$\begin{array}{l}\text { Water absorption (\%) } \\
<0.075 \text { mm grain }\end{array}$ & 0.43 & 0.57 & $\leq 2.0$ \\
$\begin{array}{l}\text { content (\%) } \\
\text { Soft stone content (\%) }\end{array}$ & 0.1 & 0.4 & $\leq 1$ \\
$\begin{array}{l}\text { LA abrasion value (\%) } \\
\text { Crushing value }\end{array}$ & 0.1 & 0.1 & $\leq 1$ \\
\hline
\end{tabular}

TABle 3: Properties of fine aggregates.

\begin{tabular}{lcc}
\hline Properties & Results & Specification requirements \\
\hline Apparent density $\left(\mathrm{g} / \mathrm{cm}^{3}\right)$ & 2.936 & $\geq 2.60$ \\
Sturdiness (\%) & 0.2 & $\leq 3$ \\
Angularity (s) & 33 & $\geq 30$ \\
\hline
\end{tabular}

Table 4: Properties of mineral filler.

\begin{tabular}{lcc}
\hline Properties & Results & Specification requirements \\
\hline Apparent density $\left(\mathrm{g} / \mathrm{cm}^{3}\right)$ & 2.700 & $\geq 2.60$ \\
Hydrophilic coefficient $(\%)$ & 0.7 & $\leq 1$ \\
Water content $(\%)$ & 0.4 & $\leq 1$ \\
\hline
\end{tabular}

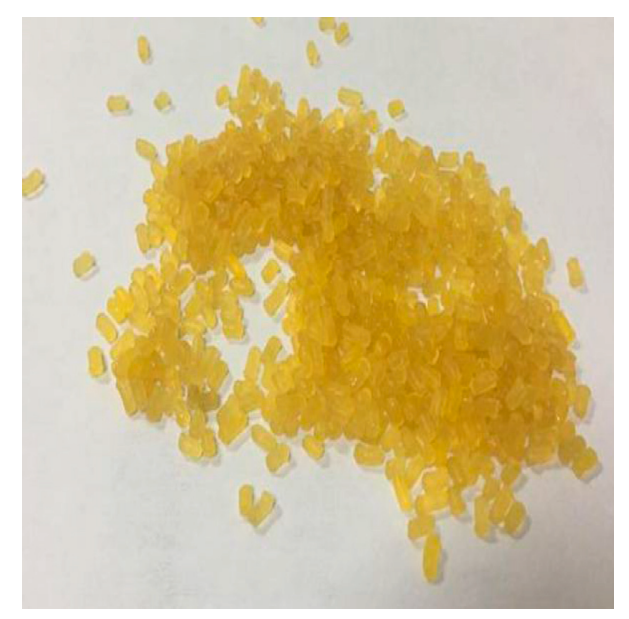

FIgURE 1: High-viscosity agent (HVA).

level of 1000. As shown in Figure 3, chopped fiber was of regular cylinders with circular cross sections and large specific surface areas, which can absorb a certain amount of asphalt binder. 
TABLE 5: Properties of the high-viscosity agent (HVA).

\begin{tabular}{lcc}
\hline Properties & Results & Specification requirements \\
\hline Density $\left(\mathrm{g} / \mathrm{cm}^{3}\right)$ & 0.985 & $0.90 \sim 1.00$ \\
Single particle quality $(\mathrm{g})$ & 0.029 & $\leq 0.03$ \\
Melt index $(\mathrm{g} / 10 \mathrm{~min})$ & 9.0 & $\geq 2.0$ \\
\hline
\end{tabular}

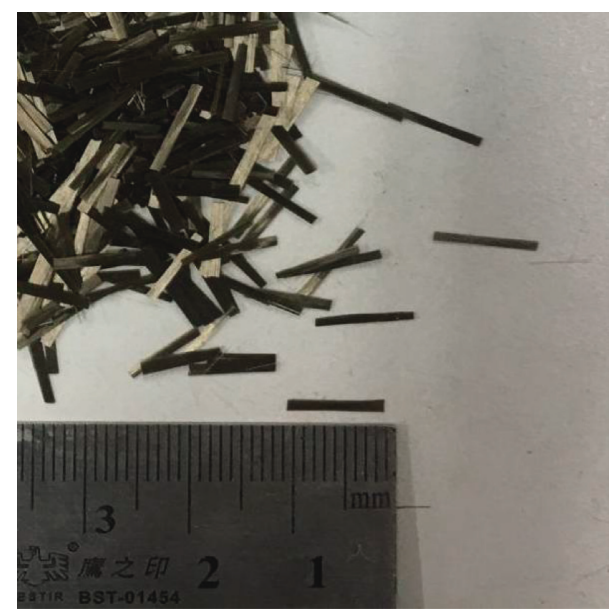

FIgURE 2: Chopped basalt fibers.

Table 6: Properties of chopped basalt fiber.

\begin{tabular}{lcc}
\hline Properties & Results & Specification requirements \\
\hline Relative density $\left(\mathrm{g} \cdot \mathrm{cm}^{-3}\right)$ & 2.71 & - \\
Length $(\mathrm{mm})$ & $3,6,9,12$ & - \\
Diameter $(\mu \mathrm{m})$ & 13 & - \\
Water content rate $(\%)$ & 0.13 & $\leq 0.2$ \\
Oil absorption rate $(\%)$ & 52 & $\geq 50$ \\
Melting point $\left({ }^{\circ} \mathrm{C}\right)$ & 1600 & - \\
Tensile strength $(\mathrm{MPa})$ & 2218 & $\geq 1200$ \\
\hline
\end{tabular}

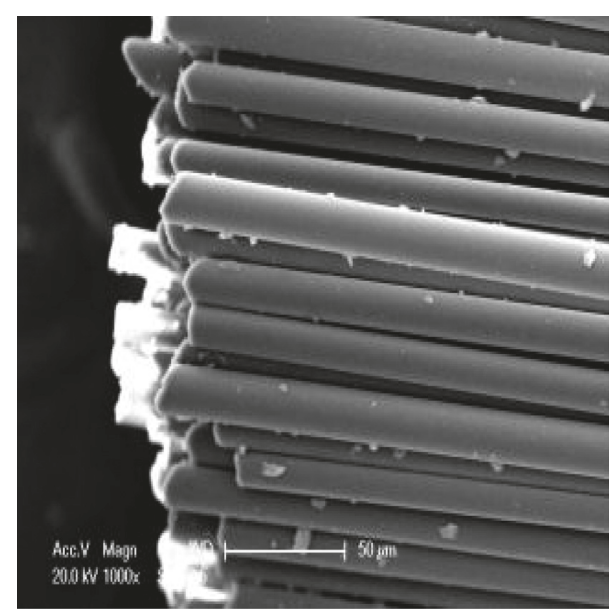

FIgURE 3: SEM micrograph of chopped basalt fibers.

Besides, some crystalline particles can be observed on the fiber surface, which results in increased surface roughness, and the anchoring effect can be formed when the fibers interact with the asphalt binder, thereby effectively improving the interfacial adhesion between the fiber and the asphalt and improving the overall performance of the asphalt mixture subsequently.

2.2. Test Methods. The test methods are illustrated in Figure 4.

2.2.1. Mixture Design. The gradation of porous asphalt mixture is presented in Table 7 .

The porous asphalt mixtures with basalt fibers were fabricated for laboratory tests according to the Chinese technical specification [25]. The minimum asphalt content was determined through Cantabro tests, and the maximum asphalt content was determined through draindown tests. Table 8 summarizes the mixture design parameters of each porous asphalt mix.

2.2.2. Draindown Test and Cantabro Abrasion Test. The draindown test and cantabro abrasion test based on JTG E20-2011 were used to evaluate the draindown resistance and antishedding ability of the porous asphalt mixture [26]. Five replicates are used for each test, and the final data are the average value of every experiment.

2.2.3. Freeze-Thaw Split Strength Test. The freeze-thaw split test was performed according to the JTG E20-2011 procedure to evaluate the water stability of the porous asphalt mixtures [26]. The Marshall specimens are compacted under 50 blows per side. After absorbing water to the saturated state in vacuum, the specimens were placed in a refrigerator at $-18^{\circ} \mathrm{C} \pm 2^{\circ} \mathrm{C}$ for $16 \mathrm{~h} \pm 1 \mathrm{~h}$. Then, the specimens were kept in a water tank at $60^{\circ} \mathrm{C} \pm 0.5^{\circ} \mathrm{C}$ for $24 \mathrm{~h}$ and then loaded at a ratio of $50 \mathrm{~mm} / \mathrm{min}$ until failure. Three replicates are used for each test, and the final data are the average value.

2.2.4. Wheel Tracking Test. The wheel tracking tests were performed according to the JTG E20-2011 procedure to evaluate the high-temperature stability of the porous asphalt mixture [26]. The wheel tracking test was conducted at $60^{\circ} \mathrm{C}$ on rectangular specimens, with the dimension of $300 \mathrm{~mm} \times 300 \mathrm{~mm} \times 50 \mathrm{~mm}$. Three replicates are used for each test, and the final data are the average value of every experiment.

2.2.5. Low-Temperature Bending Beam Test. The low-temperature bending beam test based on JTG E20-2011 was used to evaluate the low-temperature cracking resistance of the porous asphalt mixture [26]. The specimens, which were $30 \mathrm{~mm} \times 35 \mathrm{~mm} \times 250 \mathrm{~mm}$ rectangular beams, were tested to determine the bending strain at $-10^{\circ} \mathrm{C}$ with a loading rate of $50 \mathrm{~mm} / \mathrm{min}$ until cracking failure, and the load and deflection at the center of beam specimens were measured. Three replicates are used for each test, and the final data are the average value of every experiment. The bending strain was calculated according to the followingequation: 


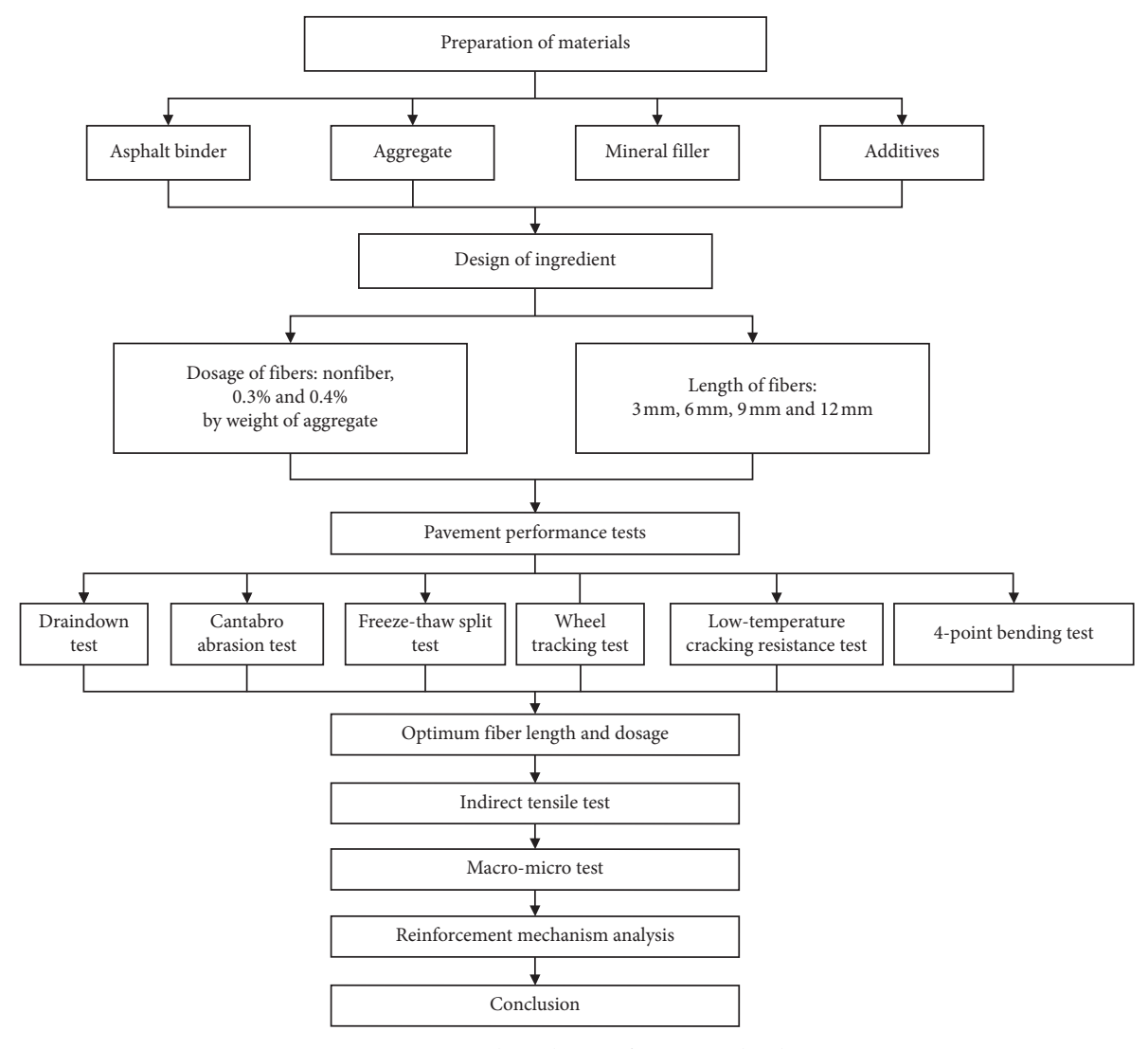

Figure 4: Flowchart of test methods.

TABle 7: Porous asphalt mixture gradation.

\begin{tabular}{lcccccccccc}
\hline $\begin{array}{l}\text { Sieve } \\
\text { size } \\
(\mathrm{mm})\end{array}$ & 16 & 13.2 & 9.5 & 4.75 & 2.36 & 1.18 & 0.6 & 0.3 & 0.15 & 0.075 \\
\hline $\begin{array}{l}\text { Passing } \\
\begin{array}{l}\text { ratio } \\
(\%)\end{array}\end{array}$ & 100.0 & 92.8 & 60.8 & 13.6 & 11.6 & 9.6 & 8.4 & 7.2 & 6.2 & 5.1 \\
\hline
\end{tabular}

TABLE 8: Design parameters of each porous asphalt mix.

\begin{tabular}{lccccc}
\hline $\begin{array}{l}\text { Mixture } \\
\text { type }\end{array}$ & No. & $\begin{array}{c}\text { Fiber } \\
\text { length } \\
(\mathrm{mm})\end{array}$ & $\begin{array}{c}\text { Fiber } \\
\text { content } \\
(\%)\end{array}$ & $\begin{array}{c}\text { Binder } \\
\text { content }(\%)\end{array}$ & $\begin{array}{c}\text { Air void } \\
(\%)\end{array}$ \\
\hline & 01 & - & - & 4.6 & 20.3 \\
& 02 & 3 & 0.3 & 4.8 & 20.1 \\
& 03 & 3 & 0.4 & 4.8 & 20.1 \\
Porous asphalt & 04 & 6 & 0.3 & 4.8 & 19.9 \\
mixture & 05 & 6 & 0.4 & 4.8 & 19.8 \\
& 06 & 9 & 0.3 & 4.8 & 19.6 \\
& 07 & 9 & 0.4 & 4.8 & 19.5 \\
& 08 & 12 & 0.3 & 4.9 & 19.3 \\
& 09 & 12 & 0.4 & 4.9 & 19.2 \\
\hline
\end{tabular}

$$
\varepsilon_{\mathrm{B}}=\frac{6 \times h \times d}{L^{2}},
$$

where $\varepsilon_{\mathrm{B}}$ is the maximum bending strain when the specimen failed, $h$ is the height of the cross section of the specimen, $d$ is the deflection of the cross section of the specimen, and $L$ is the span of the specimen.
2.2.6. Four-Point Bending Beam Fatigue Test. In this study, the four-point bending beam fatigue test was performed using an UTM-25 testing apparatus according to JTG E202011 and a rectangular beam with the dimension of $380 \mathrm{~mm} \times 63 \mathrm{~mm} \times 50 \mathrm{~mm}$ was used. A haversine loading with the frequency of $10 \mathrm{~Hz}$ was used at $15^{\circ} \mathrm{C}$, and the experiment was conducted by constant strain mode at different strain levels of 650,850 , and 1050 microstrain. Three replicates are used for each test, and the final data are the average value of every experiment.

2.2.7. Indirect Tensile Test. The indirect tensile test is used to determine the tensile properties of the asphalt mixture at a specified temperature and loading rate. This test was carried out in accordance with JTG E20-2011 [26], chopped basalt fibers with a length of $9 \mathrm{~mm}$, content of $0.3 \%$ and length of $12 \mathrm{~mm}$ and content of $0.3 \%$ were mixed into porous asphalt mixture, respectively. The test temperatures were $-25^{\circ} \mathrm{C}$, $-15^{\circ} \mathrm{C},-5^{\circ} \mathrm{C}, 5^{\circ} \mathrm{C}, 15^{\circ} \mathrm{C}$, and $25^{\circ} \mathrm{C}$, and the loading rate was $50 \mathrm{~mm} / \mathrm{min}$. The indirect tensile test is illustrated in Figure 5. Three replicates are used for each test, and the final data are the average value.

2.2.8. Fracture Morphology Analysis. The fractured section of the specimens after the indirect tensile test was chosen to observe the fracture mode by using a Nikon D5300 SLR camera and an XL-30ESEM environmental scanning electron microscope. The size of each observation section was 


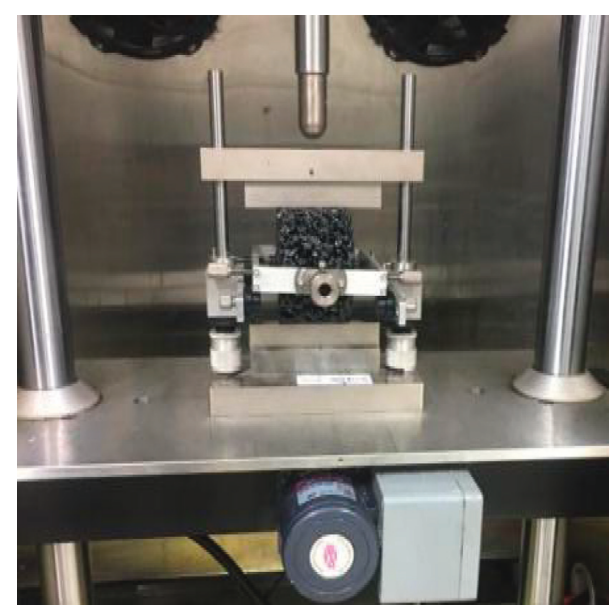

Figure 5: Indirect tensile test.

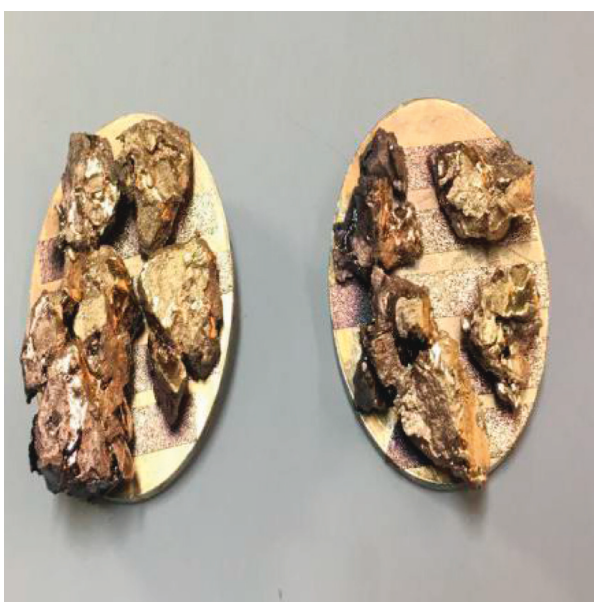

Figure 6: Sample after gold plating. approximately $20 \mathrm{~mm} \times 20 \mathrm{~mm} \times 20 \mathrm{~mm}$. The sample should be gold coated before the SEM test, as shown in Figure 6.

\section{Results and Discussion}

3.1. Pavement Performance Tests. The pavement performance results of porous asphalt mixtures are shown in Figures 7-12. The results of the draindown test and cantabro abrasion test are shown in Figures 7 and 8, respectively.

It can be seen from Figures 7 and 8 that all the results met the specification's requirements. Clearly, the porous asphalt mixture blended with chopped basalt fiber presented the lower draindown ratio and cantabro mass loss, which means that chopped basalt fiber can improve the antishedding ability of the porous asphalt mixture. As for the effect of fiber length, with the increased fiber length, the draindown ratio and cantabro mass loss firstly decreased and then increased. And the length of $9 \mathrm{~mm}$ presented the lowest values. As for the effect of fiber contents, $0.3 \%$ of fibers always presented lower values than that of $0.4 \%$ of fibers. Therefore, it referred that porous asphalt mixture blended with $9 \mathrm{~mm}$ length and $0.3 \%$ of basalt fibers acquired the best antistripping ability.

The results of freeze-thaw split strength test are shown in Figure 9.

From Figure 9, it can be seen that the tensile strength ratios of all the specimens were in the range of $81 \%-84 \%$, which met the requirement of no less than $80 \%$. However, there was no significant difference between specimens with or without $\mathrm{CBF}$, though the tensile strength ratios presented a slight increasing trend when $\mathrm{CBF}$ were used. It indicates that the chopped basalt fibers have no significant impact on the water stability of the porous asphalt mixture.

The results of the wheel tracking test are shown in Figure 10.

Based on Figure 10, all the dynamic stability (DS) results met the requirement of no less than 6000 cycles $/ \mathrm{mm}$, and compared with the no-fiber porous asphalt mixture, all the porous asphalt mixture with chopped basalt fiber presented much higher dynamic stability. As for the effect of fiber length, with the increased fiber length, the DS values firstly decreased and then increased. And the length of $9 \mathrm{~mm}$ presented the highest value. As for the effect of fiber contents, $0.3 \%$ of fibers always presented higher DS values than that of $0.4 \%$ of fibers. Therefore, it infers that porous asphalt mixture blended with $9 \mathrm{~mm}$ length and $0.3 \%$ of basalt fibers acquires the best rutting resistance ability.

The results of low-temperature bending beam test are shown in Figure 11.

It can be seen from Figure 11 that all the destructive strain results met the requirement of no less than $2800 \mu \varepsilon$. And compared with the no-fiber porous asphalt mixture, porous asphalt mixture with $3 \mathrm{~mm}$ or $6 \mathrm{~mm}$ length of CBF presented a slight increment in destructive strains. However, there was an abrupt increment in the strain when $9 \mathrm{~mm}$ length of fibers was added into the porous asphalt mixture. When using longer fibers with a length of $12 \mathrm{~mm}$, the strain was slightly reduced. As for the effect of fiber contents, similarly, $0.3 \%$ of fiber always presented higher destructive strain values than that of $0.4 \%$ of the fibers. Therefore, it refers that porous asphalt mixture blended with $9 \mathrm{~mm}$ and $0.3 \%$ of $\mathrm{CBF}$ acquires the best low-temperature cracking resistance.

The results of the four-point bending fatigue test are shown in Figure 12.

From Figure 12, it is clearly seen that porous asphalt mixtures with $\mathrm{CBF}$ have much higher cycles to failure. It means that chopped basalt fiber can significantly improve the fatigue performance of the porous asphalt mixture. For the same kind of porous asphalt mixture, the fatigue life change trend is the same under different strain modes, and the fatigue life decreases with the increase of strain. As for the effect of fiber length, with the increased fiber length, the failure cycles firstly increased and then decreased. And specimens with $9 \mathrm{~mm}$ CBF presented the highest fatigue values. As for the effect of fiber contents, $0.3 \%$ of fibers mostly presented the higher values than that of $0.4 \%$ of fibers. Therefore, it indicates that porous asphalt mixture with $9 \mathrm{~mm}$ length and $0.3 \%$ of basalt fibers shows the best fatigue performance.

From Figures 7-12, it can be seen that all of the tested performance of the designed porous asphalt mixtures can meet the specifications' requirements, and the addition of chopped 


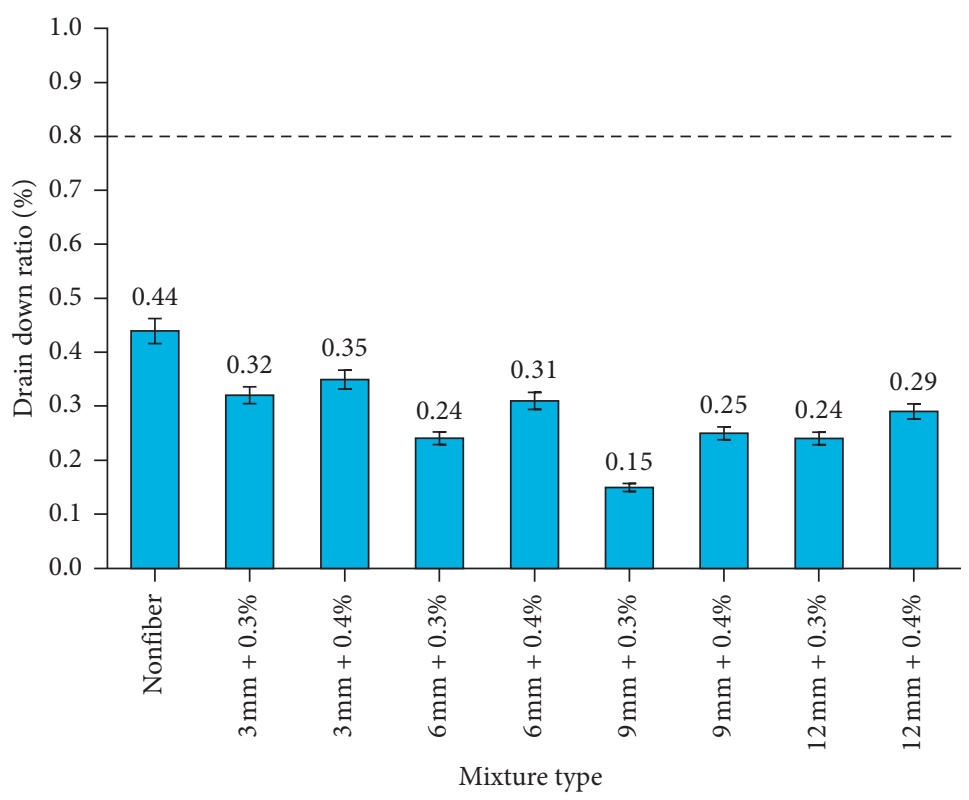

FIGURE 7: Draindown test results.

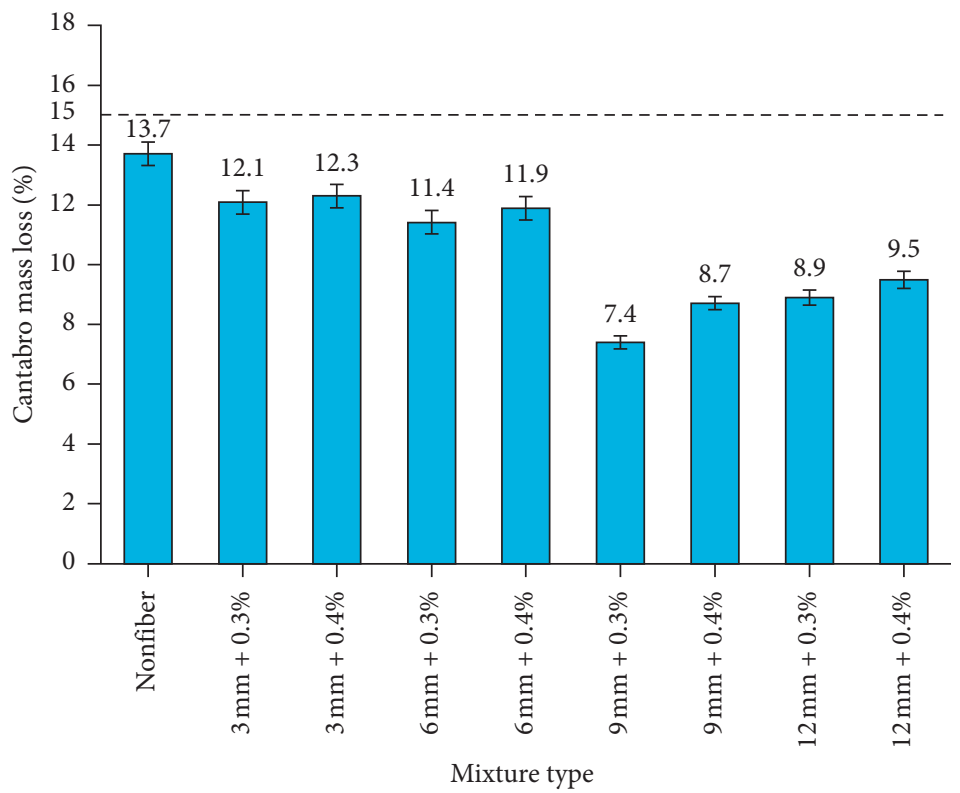

Figure 8: Cantabro abrasion test results.

basalt fibers can generally improve the performances of the porous asphalt mixtures. Furthermore, the fiber length and content did impact the performance to some extent. Porous asphalt mixture with $9 \mathrm{~mm}$ length and $0.3 \%$ of basalt fibers acquires the best pavement performance and followed by the mixtures with $12 \mathrm{~mm}$ length and $0.3 \%$ of fibers.

3.2. Indirect Tensile Strength Test at Different Temperatures. The tensile properties of the porous asphalt mixture can indicate the thermal cracking resistance performance. Therefore, it is important to further study the effects of chopped basalt fiber on the tensile properties of porous asphalt mixtures. Indirect tensile tests were explored to evaluate the tensile properties of porous asphalt mixtures at different temperatures. According to the results of Figures 7-12, samples with CBF of $9 \mathrm{~mm}, 12 \mathrm{~mm}$ length, and $0.3 \%$ content were used. The indirect tensile strengths of porous asphalt mixtures and temperature are plotted in Figure 13.

As can be seen from Figure 13, the addition of both $9 \mathrm{~mm}$ and $12 \mathrm{~mm}$ CBF provides a considerable positive effect on the tensile strength of the porous asphalt mixture at all the test temperatures. For instance, compared with no-fiber mixtures, the indirect tensile strength of porous asphalt mixture with fibers increased by $7.1 \%$ and $46 \%$ at $-25^{\circ} \mathrm{C}$ and $25^{\circ} \mathrm{C}$, respectively. Furthermore, with the increasing temperature, the indirect tensile strength of all mixtures with 


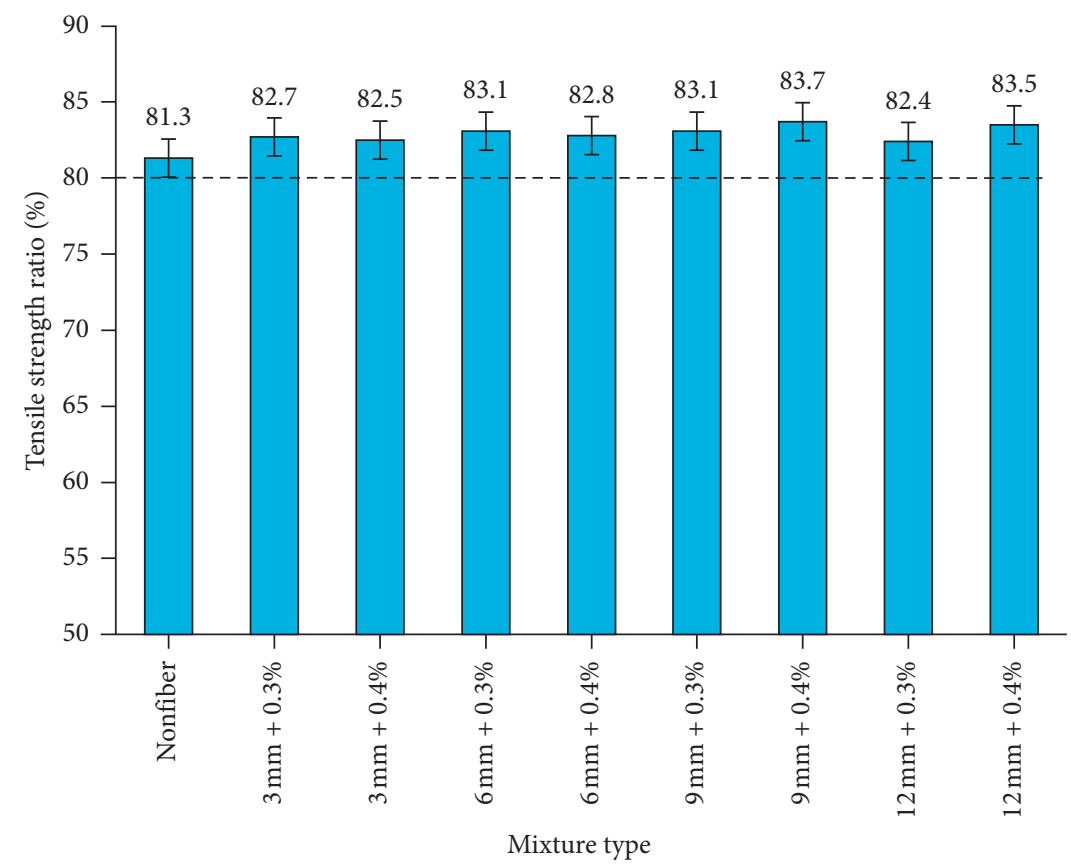

FIgURE 9: Freeze-thaw split test results.

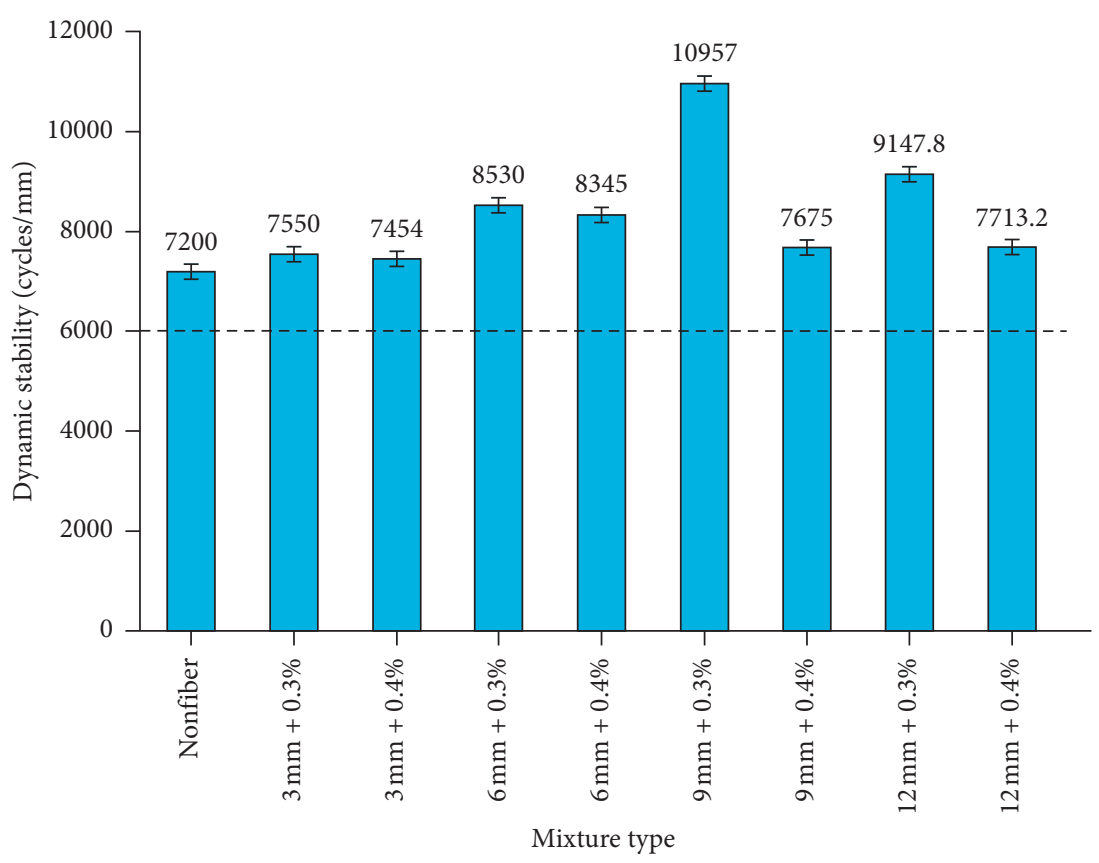

FIGURE 10: Wheel tracking test results.

fibers increased firstly from $-25^{\circ} \mathrm{C}$ to $-5^{\circ} \mathrm{C}$ and then decreased from $-5^{\circ} \mathrm{C}$ to $25^{\circ} \mathrm{C}$, and the indirect tensile strength reaches the highest point when the temperature is $-5^{\circ} \mathrm{C}$. It was also observed that fiber length had no obvious impact on the indirect tensile strength. However, mixtures with $9 \mathrm{~mm}$ fibers presented higher indirect tensile strength at several temperatures. Thus, combined with the results from Figures $7-12,9 \mathrm{~mm}$ length and $0.3 \%$ content of fiber is recommended to improve the tensile properties of the porous asphalt mixture.
3.3. Morphology Analysis. The morphology of fracture sections of the samples is highly related to the temperatures. When the temperature is over $10^{\circ} \mathrm{C}$, the samples cannot produce a fracture section by indirect tensile tests. Therefore, typical fracture sections of samples from indirect tensile tests (ITTs) at the temperatures of $-15^{\circ} \mathrm{C},-5^{\circ} \mathrm{C}$, and $5^{\circ} \mathrm{C}$ were selected for morphology analysis, and the results are shown in Figures 14-16. Porous asphalt mixture is a type of continuous open-grade asphalt mixture, which presents three typical cracking mode aggregate fractures, asphalt tack coat 


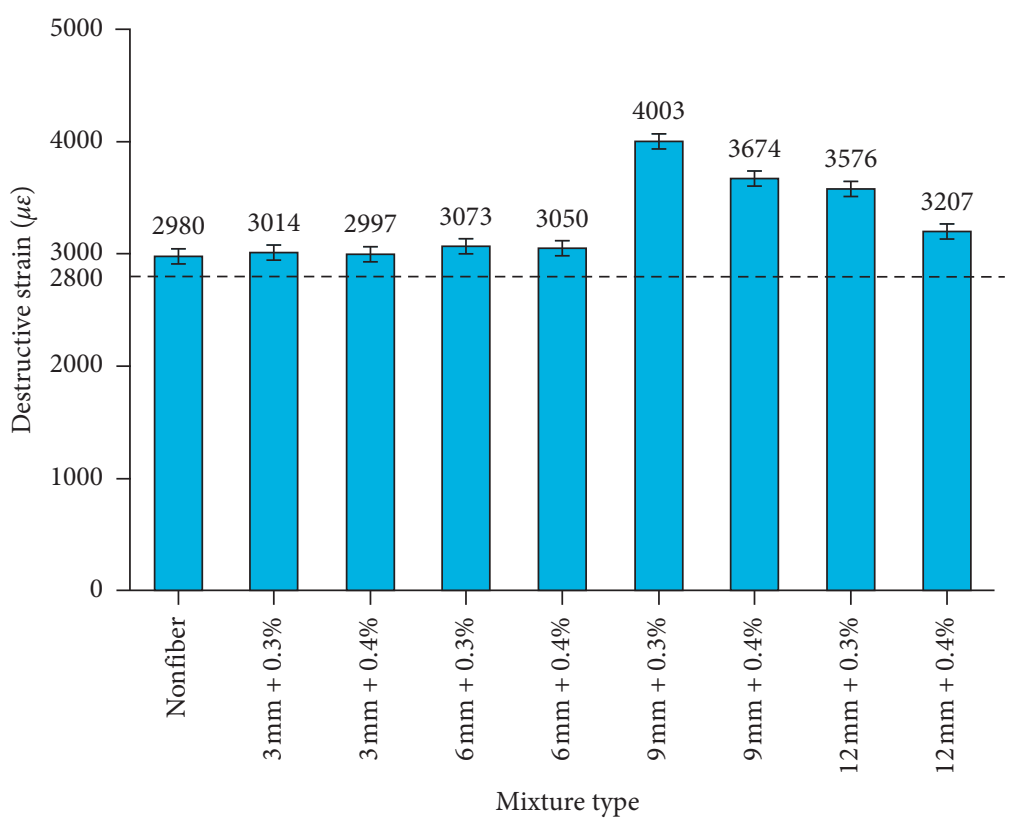

FIGURE 11: Low-temperature bending test results.

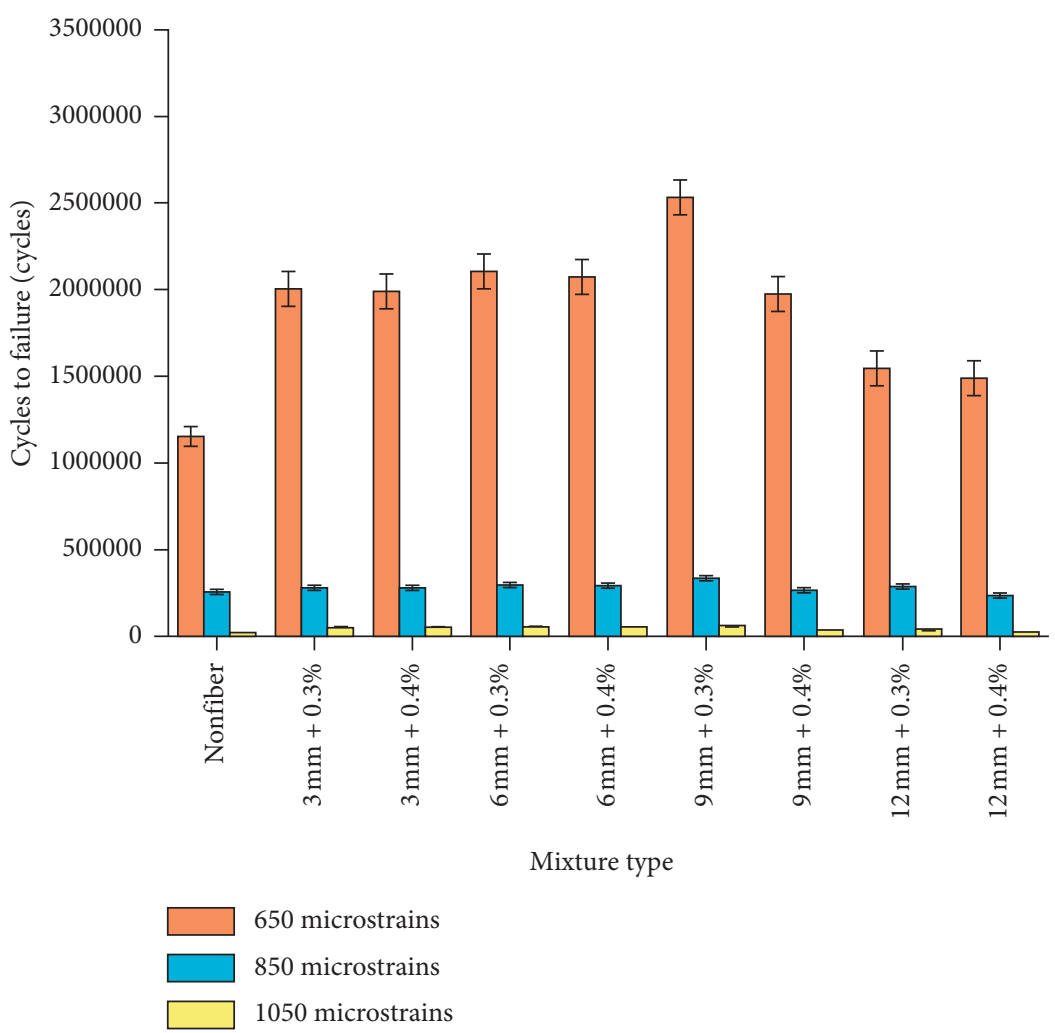

FIgURE 12: Four-point bending beam fatigue test results.

fracture, and asphalt mortar layer fracture [27]. As shown in Figures 14-16, the aggregate fracture is grayish white (marked as green dots); the asphalt tack coat fracture is grayish black, and fracture is relatively smooth, and the fracture of the asphalt mortar layer is black and white [28].

It can be seen from Figures 14-16 that the fracture sections of all the three types of samples from $-5^{\circ} \mathrm{C}$ ITT presented much more grayish white parts than the samples from $-15^{\circ} \mathrm{C}$ and $5^{\circ} \mathrm{C} \mathrm{ITT}$, and the fracture sections of all the three types of samples from $-15^{\circ} \mathrm{C}$ ITT presented more grayish white parts than the samples from $5^{\circ} \mathrm{C}$ ITT. It indicates that at $-5^{\circ} \mathrm{C}$, aggregate fracture became an important contributor to the total indirect tensile fracture failure, along with asphalt tack coat fracture and asphalt mortar layer 


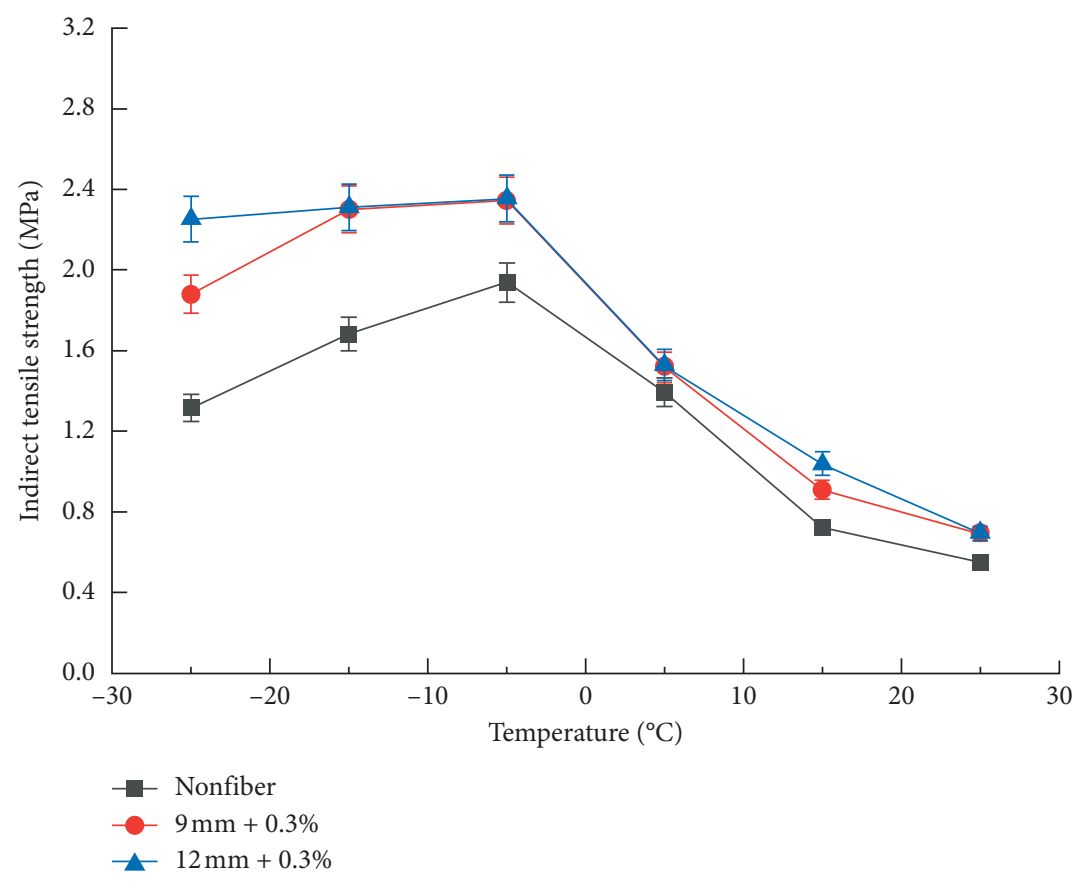

FIGURE 13: Results of indirect tensile strength.

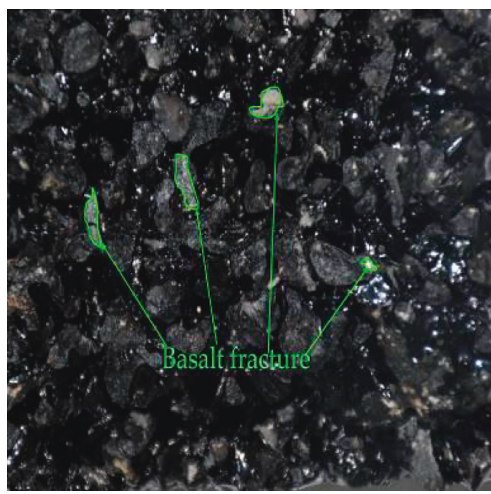

(a)

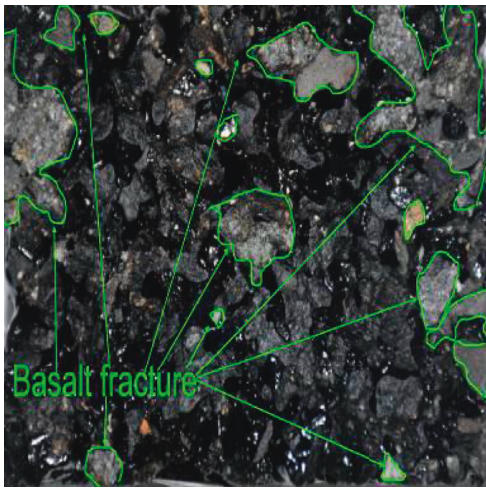

(b)

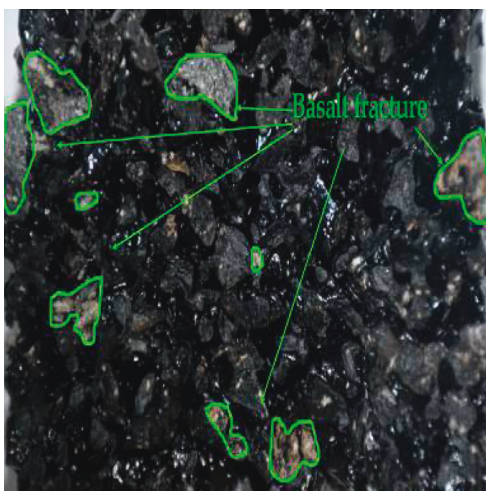

(c)

Figure 14: Typical sections of no-fiber samples. (a) $5^{\circ} \mathrm{C}$. (b) $-5^{\circ} \mathrm{C}$. (c) $-15^{\circ} \mathrm{C}$.

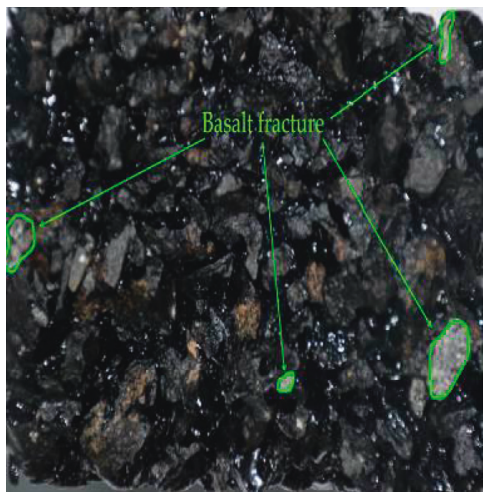

(a)

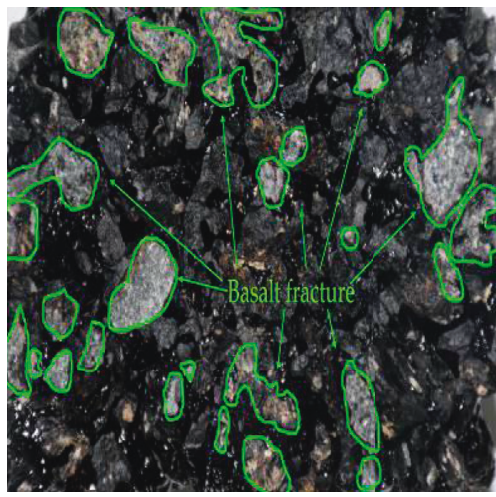

(b)

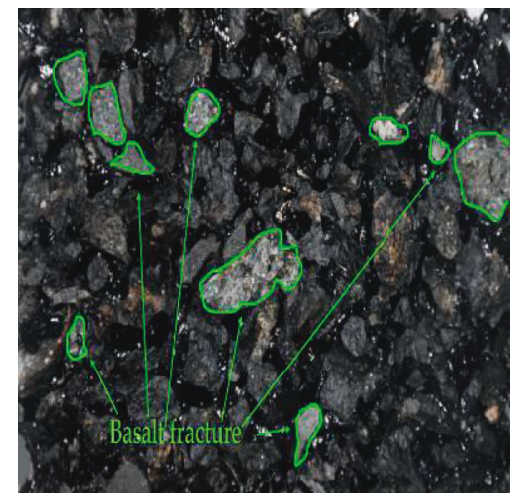

(c)

Figure 15: Typical sections of samples with fibers of $9 \mathrm{~mm}+0.3 \%$. (a) $5^{\circ} \mathrm{C}$. (b) $-5^{\circ} \mathrm{C}$. (c) $-15^{\circ} \mathrm{C}$. 


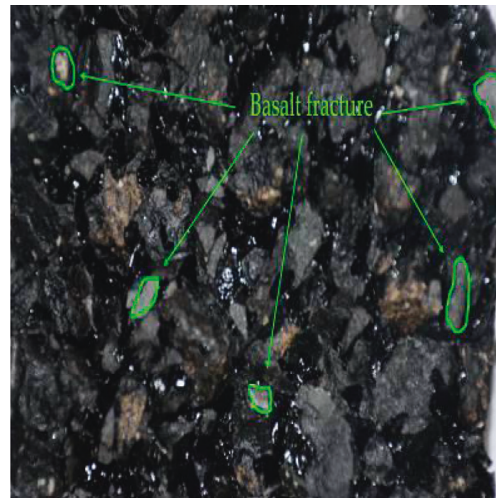

(a)

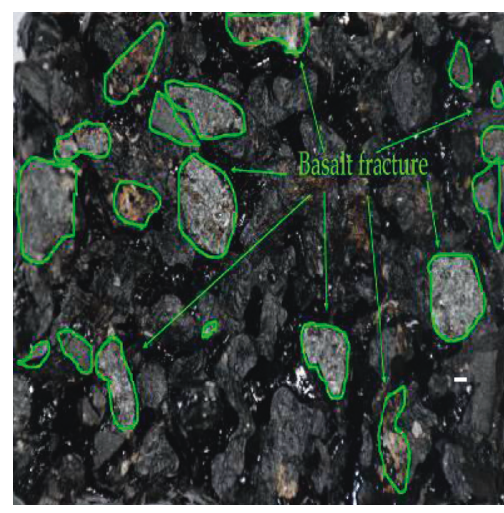

(b)

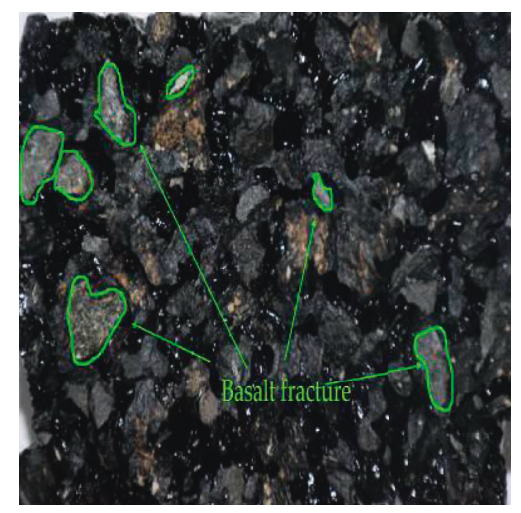

(c)

Figure 16: Typical sections of samples with fibers of $12 \mathrm{~mm}+0.3 \%$. (a) $5^{\circ} \mathrm{C}$. (b) $-5^{\circ} \mathrm{C}$. (c) $-15^{\circ} \mathrm{C}$.

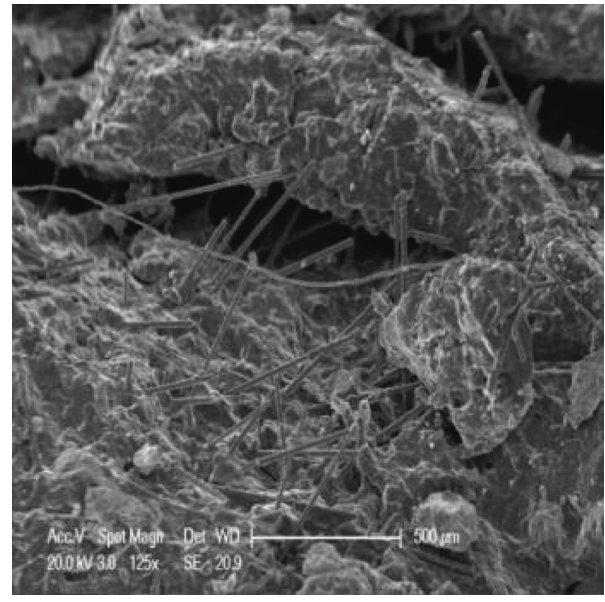

FIGURE 17: SEM micrographs of the crack of the porous asphalt mixture.

fracture. Since the strength of the basalt aggregates themselves becomes a part of the indirect tensile strength of the whole test specimen, the tensile strength of the porous asphalt mixture at $-5^{\circ} \mathrm{C}$ is much higher than that at $5^{\circ} \mathrm{C}$ and $-15^{\circ} \mathrm{C}$. At $-15^{\circ} \mathrm{C}$, asphalt turns stiffer, and the mortar layer fracture becomes the dominant fracture mode. As a result, the tensile strength at $-15^{\circ} \mathrm{C}$ is lower than that at $-5^{\circ} \mathrm{C}$ but higher than that at $5^{\circ} \mathrm{C}$, which is consistent with the results from Figure 13.

3.4. Microstructure Analysis by SEM. Samples with $9 \mathrm{~mm}$ length and $0.3 \%$ of fibers after $-5^{\circ} \mathrm{C}$ ITT were selected for microstructure analysis by XL-30ESEM environmental scanning electron microscopy. Typical fiber distribution in porous asphalt mixture is shown in Figure 17. Interface between $\mathrm{CBF}$ and asphalt is shown in Figure 18.

It can be observed from Figure 17 that the chopped basalt fibers are randomly distributed in the asphalt mixture. However, the distribution formed a three-dimensional spatial network structure, which is significant for the reinforcement of asphalt mixtures. The three-dimensional

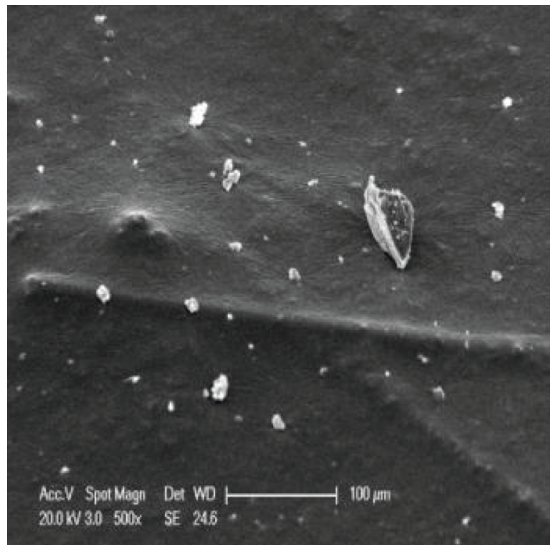

(a)

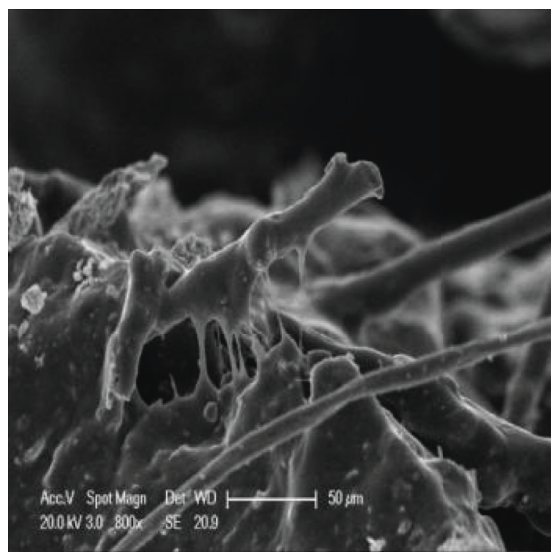

(b)

FIGURE 18: SEM micrographs of bonding interface between the fiber and asphalt. (a) Asphalt wrapped with chopped basalt fiber; (b) distribution of fibers in asphalt.

network structure cannot only bear and transfer stress but also improve the inner defects of the asphalt mixtures. Moreover, it can enhance the integrity of the asphalt mixtures so as to prevent crack propagation.

In Figure 18(a), chopped basalt fiber is dispersed in the asphalt and has good wettability with asphalt, and it absorbs 
a part of free asphalt and makes it become structural asphalt. Meanwhile, chopped basalt fiber can absorb a certain amount of asphalt so as to maintain the free asphalt, resulting in a positive improvement effect on the asphalt mixture performance.

In Figure 18(b), the surface of the fiber is covered with asphalt, which means the chopped basalt fiber is well bonded to the asphalt. Furthermore, even the broken end of the BCF was covered with asphalt, indicating an excellent interface bonding force between the chopped basalt fiber and the asphalt.

\section{Conclusions}

According to the results of this study, the following conclusions can be drawn:

(1) The addition of chopped basalt fibers can improve the pavement performance of porous asphalt mixture, and the recommended length and content of fiber are $9 \mathrm{~mm}$ and $0.3 \%$, respectively.

(2) The addition of chopped basalt fiber can improve the indirect tensile strength of porous asphalt mixture. No obvious difference was observed between the $9 \mathrm{~mm}$ and $12 \mathrm{~mm}$ length of fibers. The indirect tensile strength reaches the maximum value at $-5^{\circ} \mathrm{C}$.

(3) At $-5^{\circ} \mathrm{C}$, the strength of aggregates contributes to the indirect tensile strength of the test sample, resulting in the maximum indirect tensile strength.

(4) The chopped basalt fiber is well combined with the asphalt and distributed in a three-dimensional network structure in the porous asphalt mixture, which can reinforce the performance of asphalt mixture significantly.

\section{Data Availability}

The data used to support the findings of this study are available from the corresponding author upon request.

\section{Conflicts of Interest}

The authors declare that they have no conflicts of interest regarding the publication of this paper.

\section{Acknowledgments}

The authors would like to appreciate the financial support of the National Natural Science Foundation of China (nos. 51578481 and 51578480), the Practice and Innovation Plans for Graduates of Yangzhou University (XSJCX17_023), and Natural Science Foundation of the Higher Education Institutions of Jiangsu Province (16KJB580010).

\section{References}

[1] T.-W. Hsu, S.-C. Chen, and K.-N. Hung, "Performance evaluation of asphalt rubbr in porous asphalt-concrete mixtures," Journal of Materials in Civil Engineering, vol. 23, no. 3, pp. 342-349, 2011.
[2] D. M. Colwill, G. J. Bowskill, J. C. Nicholls, and M. E. Daines, "Porous asphalt trials in the United Kingdom," Transportation Research Record, pp. 13-21, 1994.

[3] T. F. Fwa, S. A. Tan, C. T. Chuai, and Y. K. Guwe, "Expedient permeability measurement for porous pavement surface," International Journal of Pavement Engineering, vol. 2, no. 4, pp. 259-270, 2001.

[4] K. W. Kim and M. E. Hussein, "Variation of fracture toughness of asphalt concrete under low temperatures," Construction and Building Materials, vol. 11, no. 7-8, pp. 403-411, 1997.

[5] E. Zegeye, J.-L. Turos, M. Turos, and M. Marasteanu, "Investigation of size effect in asphalt mixture fracture testing at low temperature," Road Materials and Pavement Design, vol. 13, no. 1, pp. 88-101, 2012.

[6] X. Li and M. Marasteanu, "The fracture process zone in asphalt mixture at low temperature," Engineering Fracture Mechanics, vol. 77, no. 7, pp. 1175-1190, 2010.

[7] S. M. Abtahi, M. Sheikhzadeh, and S. Mahdi Hejazi, "Fiberreinforced asphalt-concrete-a review," Construction and Building Materials, vol. 24, no. 6, pp. 871-877, 2010.

[8] S. Tapkin, "The effect of polypropylene fibers on asphalt performance," Building \& Environment, vol. 43, no. 6, pp. 1065-1071, 2008.

[9] Y. Z. Chen and Z. X. Li, "Study of road property of basalt fiber asphalt concrete," Applied Mechanics and Materials, vol. 238, pp. 22-25, 2012.

[10] J. Sim, C. Park, and D. Y. Moon, "Characteristics of basalt fiber as a strengthening material for concrete structures," Composites Part B: Engineering, vol. 36, no. 6-7, pp. 504-512, 2005.

[11] K. Krayushkina, O. Prentkovskis, A. Bieliatynskyi et al., "Perspectives on using basalt fiber filaments in the construction and rehabilitation of highway pavements and airport runways," Baltic Journal of Road \& Bridge Engineering, vol. 11, no. 1, pp. 77-83, 2016.

[12] B. J. Putman and S. N. Amirkhanian, "Utilization of waste fibers in stone matrix asphalt mixtures," Resources, Conservation and Recycling, vol. 42, no. 3, pp. 265-274, 2004.

[13] J.-S. Chen and K.-Y. Lin, "Mechanism and behavior of bitumen strength reinforcement using fibers," Journal of $\mathrm{Ma}$ terials Science, vol. 40, no. 1, pp. 87-95, 2005.

[14] N. Morova, "Investigation of usability of basalt fibers in hot mix asphalt concrete," Construction and Building Materials, vol. 47, no. 10, pp. 175-180, 2013.

[15] W. X. Fan, S. F. Zhang, and L. Q. Liu, "Laboratory study of marshall of basalt fiber-modified asphalt mixture," Applied Mechanics \& Materials, vol. 256-259, pp. 1851-1857, 2013.

[16] J. Wu, R. Hong, and C. Gu, "Influence of fiber type on lowtemperature fracture performance of presawed asphalt mixture beams," Advances in Materials Science and Engineering, vol. 2018, Article ID 5087395, 7 pages, 2018.

[17] J. Singletary, R. W. Baines, W. Beckett, and K. Friedrich, "Examination of fundamental assumptions of an analytical model of fiber pull-out test," Mechanics of Composite Materials \& Structures, vol. 4, no. 2, pp. 95-112, 1997.

[18] C. Yongchun, Z. Chunfeng, T. Guojin et al., "Laboratory study on properties of diatomite and basalt fiber compound modified asphalt mastic," Advances in Materials Science and Engineering, vol. 2017, Article ID 4175167, 10 pages, 2017.

[19] R. Muniandy and B. B. K. Huat, "Laboratory diameteral fatigue performance of stone matrix asphalt with cellulose oil palm fiber," American Journal of Applied Sciences, vol. 3, no. 9, pp. 2005-2010, 2006. 
[20] Y. Gao, Q. Guo, Y. Guo, P. Wu, W. Meng, and T. Jia, "Investigation on reinforced mechanism of fiber reinforced asphalt concrete based on micromechanical modeling," Advances in Materials Science and Engineering, vol. 2017, Article ID 4768718, 12 pages, 2017.

[21] S. Wu, Q. Ye, N. Li, and H. Yue, "Effects of fibers on the dynamic properties of asphalt mixtures," Journal of Wuhan University of Technology-Materials Science Edition, vol. 22, no. 4, pp. 733-736, 2007.

[22] Z. Chen, S. P. Wu, Z. H. Zhu, and J. S. Liu, "Experimental evaluation on high temperature rheological properties of various fiber modified asphalt binders," Journal of Central South University of Technology, vol. 15, no. S1, pp. 135-139, 2008.

[23] A. Mahrez, M. R. Karim, and H. Y. B. Katman, "Fatigue and deformation properties of glass fiber reinforced bituminous mixes," Journal of the Eastern Asia Society for Transportation Studies, vol. 6, pp. 997-1007, 2008.

[24] S. Serin, N. Morova, M. Saltan, and S. Terzi, "Investigation of usability of steel fibers in asphalt concrete mixtures," Construction and Building Materials, vol. 36, no. 4, pp. 238-244, 2012.

[25] The Ministry of Communications of the People's Republic of China, Technical Specifications for Construction of Highway Asphalt Pavements, The Ministry of Communications of the People's Republic of China, Beijing, China, 2005.

[26] The Ministry of Communications of the People's Republic of China, Standard Test Methods of Bitumen and Bituminous Mixtures for Highway Engineering, The Ministry of Communications of the People's Republic of China, Beijing, China, 2011.

[27] L. Mo, M. Huurman, S. Wu, and A. A. A. Molenaar, "Ravelling investigation of porous asphalt concrete based on fatigue characteristics of bitumen-stone adhesion and mortar," Materials \& Design, vol. 30, no. 1, pp. 170-179, 2009.

[28] L. H. Zhao, J. Y. Chen, and S. W. Wang, "Analysis of the crack fracture morphology of the asphalt mixture under tensile stress effects," Advanced Materials Research, vol. 250-253, pp. 3533-3537, 2011. 


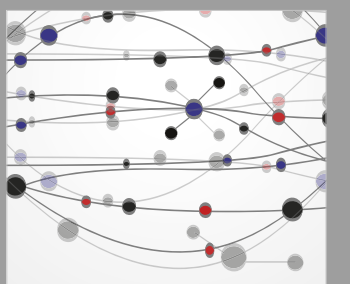

The Scientific World Journal
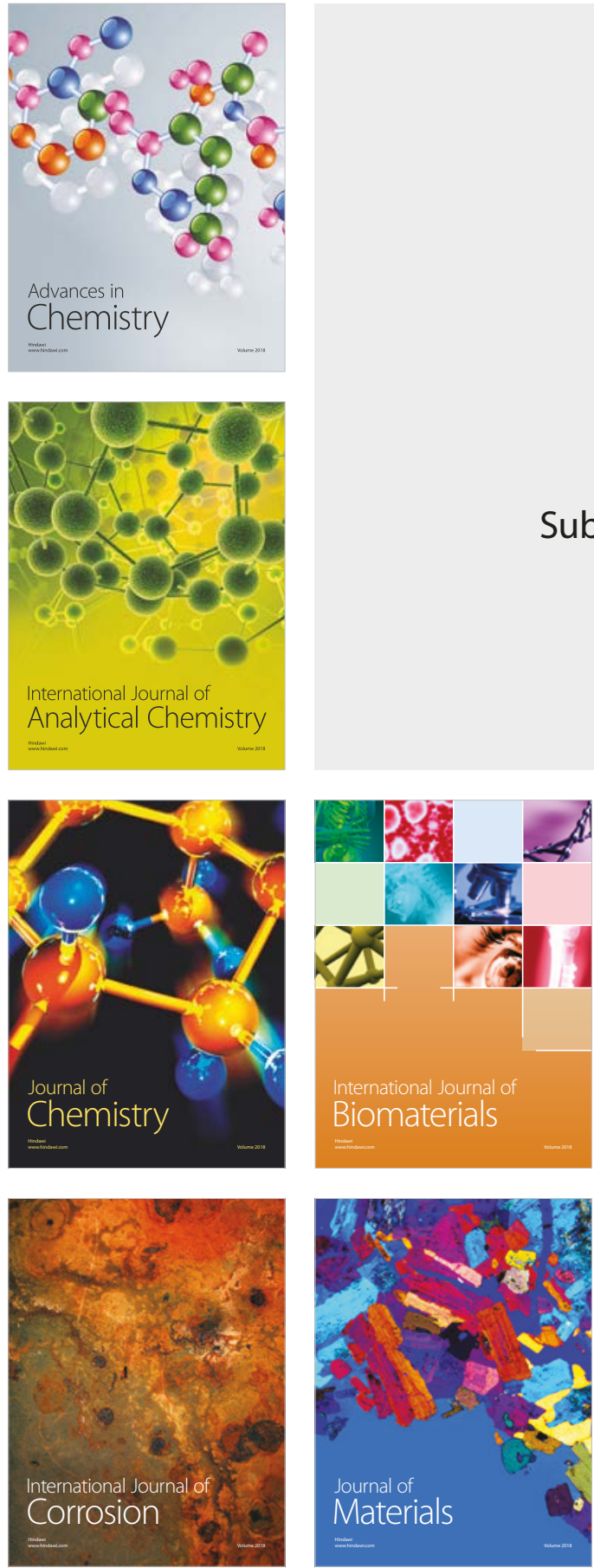

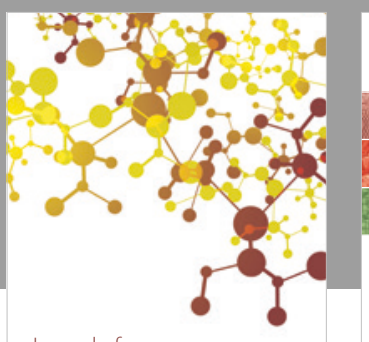

Journal of

Applied Chemistry
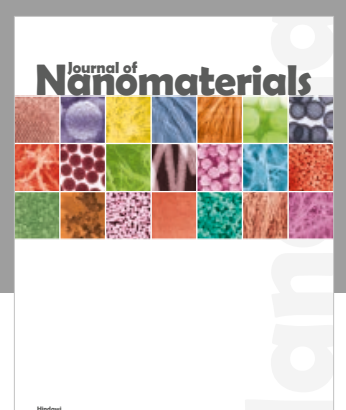

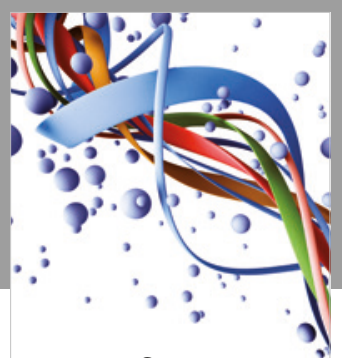

Scientifica

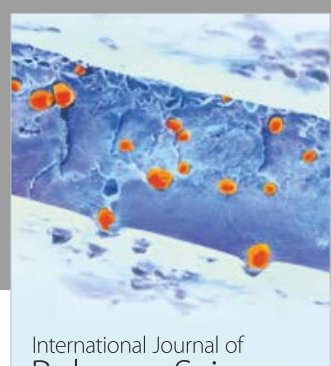

Polymer Science

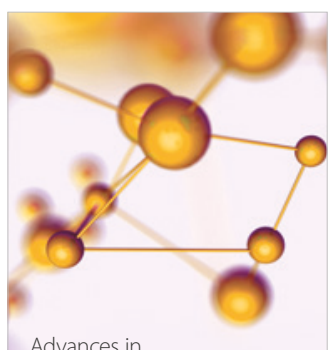

Physical Chemistry
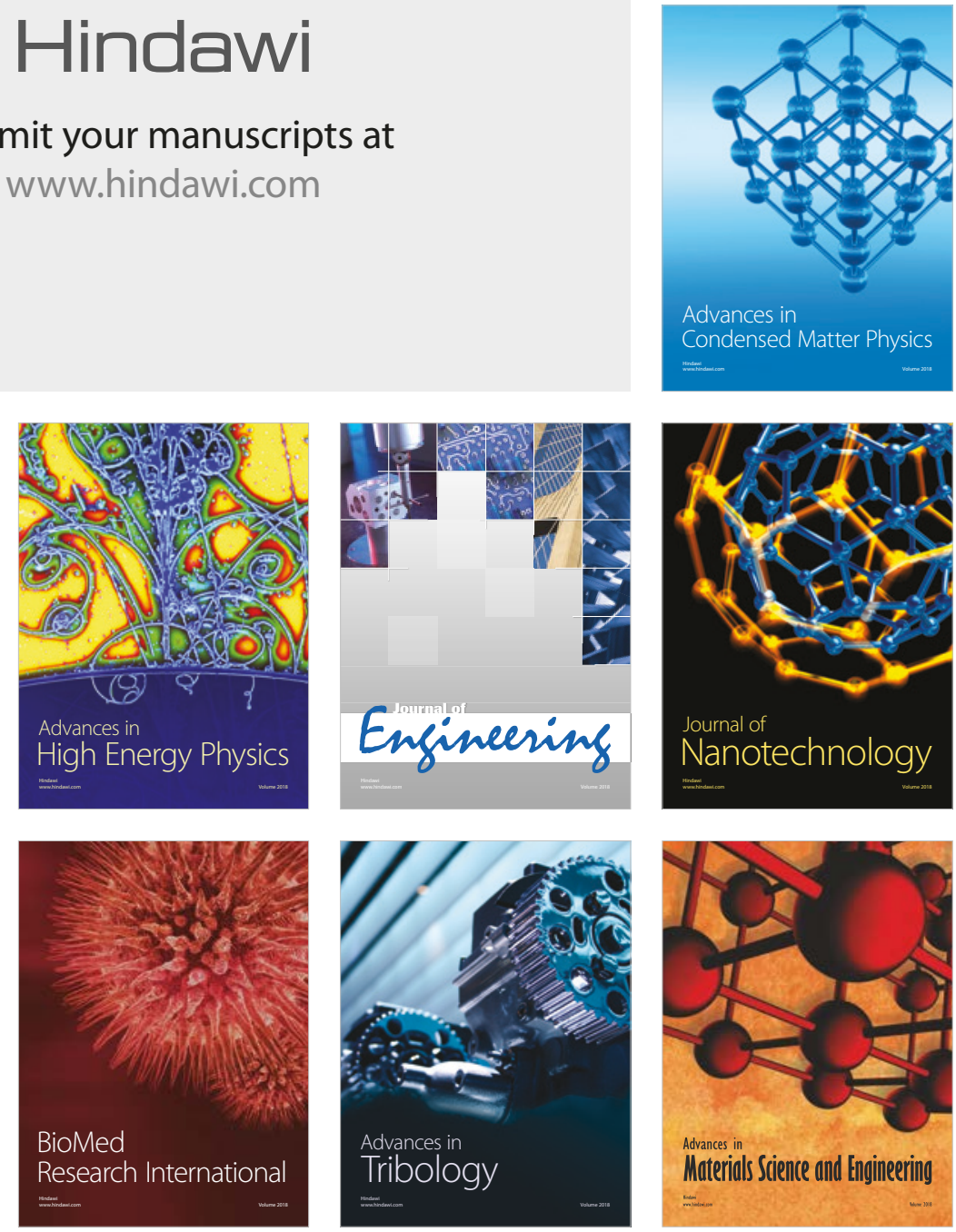